\title{
Afinal, quem é mais moderno neste país?
}

MÁrCIO SOUZA

$\mathrm{N}$

A AMÉRICA LATINA nunca aconteceu nada parecido como a Guerra da Secessão americana, porém, em cada um dos países latinos houve, em determinado momento de sua história, um confronto entre modelos de sociedade, de choques entre propostas avançadas, modernas e posições atrasadas e retrógradas. O exemplo da Guerra da Secessão americana, em que uma nação não apelou para a conciliação e foi capaz de derramar sangue para decidir princípios, sempre causa uma impressão forte, especialmente em um país como o Brasil, onde o mito da história incruenta serviu, durante muito tempo, para mascarar os nossos desacertos. Agora, porém, já se sabe. Aqui muito sangue também foi derramado e princípios também estiveram em jogo. Basta relembrar como foram os trágicos anos vividos pelo então Grão-Pará entre 1823 e 1840.

Para que se compreenda a questão, um fato deve ficar claro desde já: em 1822 a Amazônia não fazia parte do Brasil. Sequer se chamava Amazônia.

Na verdade, os portugueses construíram duas colônias na América do Sul. Pode-se mesmo acreditar que esta não foi uma decisão administrativa dos portugueses, mas uma conseqüência das limitações tecnológicas. Naqueles tempos de navegação a vela, a transposição do cabo Branco era praticamente impossível e perigoso. Assim, para os que vinham do Atlântico Norte, as rotas mais propícias eram aquelas que, seguindo as correntes, levavam diretamente ao Atlântico Sul e ao litoral do Brasil, ou as que levavam ao Caribe e ao estuário do rio Amazonas. Uma viagem do Rio de Janeiro para Lisboa em 1790 durava noventa dias; uma entre Belém e Lisboa na mesma época durava trinta dias; já outra entre o Rio de Janeiro e Belém podia durar até cinco meses.

O certo, então, é que tínhamos duas colônias de língua portuguesa na América do Sul. Uma descoberta por Cabral em 1500, batizada com o nome de Brasil e administrada por governadores gerais e vice-reis, com capital no Rio de Janeiro e um território que, ao norte, começava nos limites do atual estado do Piauí, descendo por uma estreita faixa pelo litoral nordestino, passando por Goiás, Minas Gerais e estendendo-se até as margens do rio da Prata, hoje o Uruguai. A outra colônia, inicialmente conhecida como Grão-Pará e Maranhão e mais tarde como Grão-Pará e Rio Negro, foi descoberta por Vicente Iañes Pinzón, em 1498, logo após a terceira viagem de Colombo à América, quando batizou o rio Amazonas de mar Dulce, mas efetivamente ocupada pelos portugueses a partir de 1630. Essa colônia tinha em seu território o equivalente à reunião dos atuais 
estados do Maranhão, Pará, Amapá, Amazonas, Roraima, Rondônia e parte do Acre. A capital era Santa Maria de Belém e era administrada por governadores militares e administradores diretamente ligados a Lisboa. Essas duas administrações coloniais se desenvolveram distintamente até 1823, data em que o Império do Brasil começou a anexar a colônia nortista. Uma nota curiosa: os habitantes da colônia do Sul eram chamados de brasileiros, os do norte de portuguesesamericanos.

A independência do Brasil em 1822 pouco reflexo teve no território do Grão-Pará. Alguns adeptos da idéia da independência, como Felipe Patroni, e o cônego Batista Campos desejavam cortar os laços com a Metrópole, mas estavam completamente isolados do Rio de Janeiro, mantendo contatos e trocas de correspondência apenas com as lideranças do nordeste. A notícia da proclamação do príncipe Pedro de Alcântara, herdeiro da casa de Bragança, trouxe muita desconfiança, embora o gesto tenha aguçado o desejo de repetir o feito na progressista colônia ao norte. Um jornal, editado por Patroni, o primeiro a circular na Amazônia, O Paraense, pregou o corte dos laços com Portugal, mas apenas por alguns meses de 1822, sendo fechado e seu proprietário perseguido. Em março do 1823, o cônego Batista Campos consegue eleger para a legislatura de Belém uma maioria de brasileiros, mas os portugueses anulam as eleições. Em abril, um levante propondo a adesão ao Império do Brasil é esmagado e seus participantes deportados para Lisboa, onde são condenados à morte. Finalmente, em agosto, aporta em Belém o brigue Maranhão, comandado por John Pascoe Greenfell, mercenário inglês sob o comando do almirante Cochrane e a soldo do Império do Brasil. Greenfell, que estava com 21 anos, inaugura o modelo de relação que o governo central do Brasil teria com a Amazônia a partir de então: o blefe. No dia 11 de agosto, depois de espalhar o boato de que a esquadra de Cochrane estava fundeada nas proximidades, Greenfell enviou um ultimato aos governantes portugueses para que depusessem as armas ou aderissem ao Império do Brasil. Caso recusassem, Belém sofreria um bombardeio naval.

A maioria dos portugueses e quase toda a burocracia colonial aderiram incondicionalmente e os nacionalistas viram-se alijados do poder. Da mesma forma que no recôncavo baiano e em Pernambuco, a administração de José Bonifácio preferia apostar nas lideranças conservadoras, geralmente portugueses de fortuna adquirida na colônia, do que apoiar líderes brasileiros não exatamente afinados com o espírito da casa de Bragança. De 1823 para frente o que vai se ver é o constante embate entre as correntes conservadoras e nacionalistas, os primeiros com o Partido Caramuru e os segundos com a Sociedade Filantrópica. As refregas políticas invariavelmente acabavam em choques armados.

Aqui é pertinente uma pergunta. Por que a violência tornou-se a única via possível? Onde estava o espírito conciliador ciosamente cultivado pelas nossas elites? A melhor explicação está na profunda diferença entre as duas colônias, tão distintas que eram em estratégias, na cultura, na economia e até na visão de mundo. 


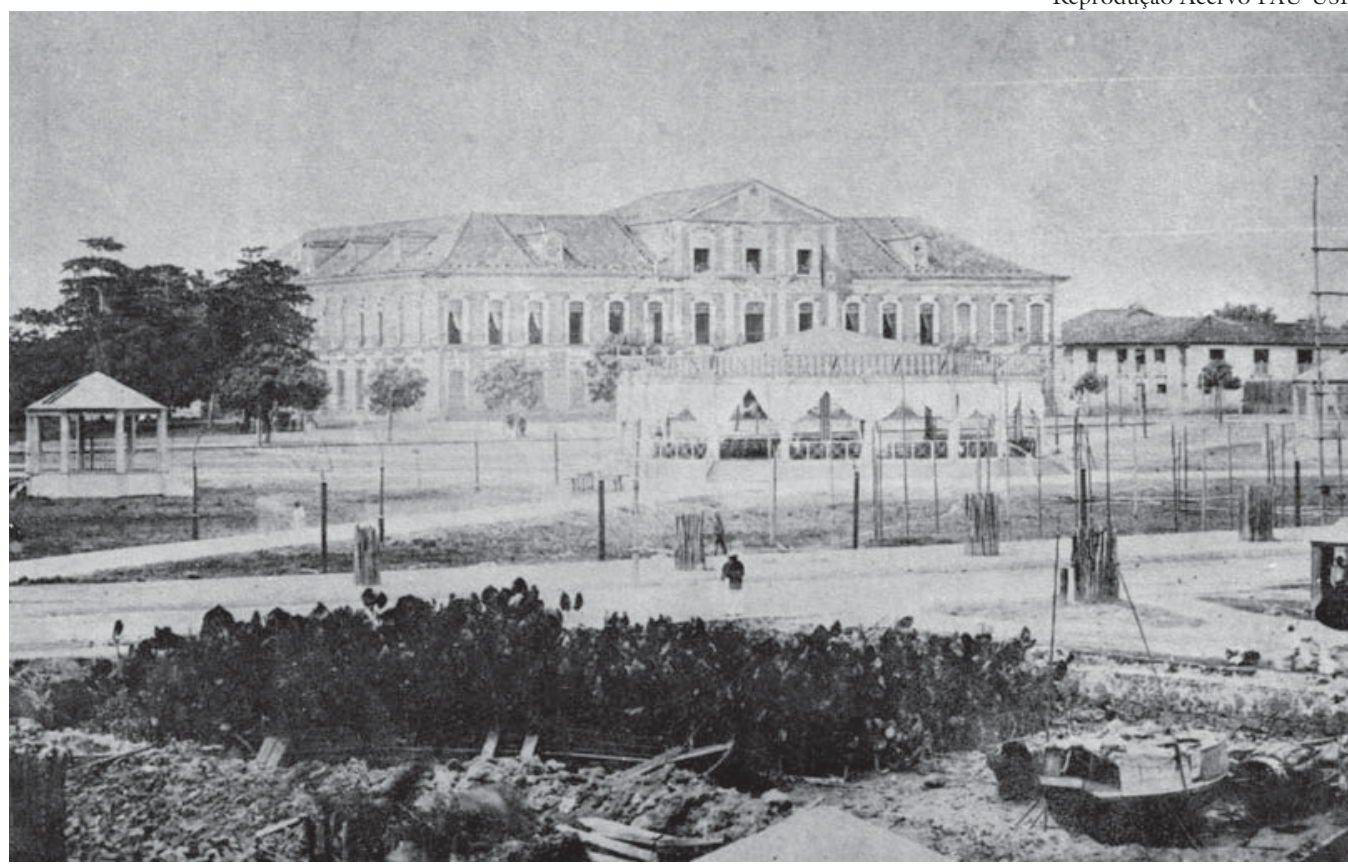

Fotografia de 1867 por ocasião dos festejos da abertura do rio Amazonas ao comércio mundial.

A verdadeira fundação do estado do Grão Pará e Maranhão se deu em 31 de julho de 1751, com a assinatura do decreto pelo Marquês de Pombal. Para governar o novo Estado Pombal nomeia seu irmão Xavier de Mendonça Furtado, que imediatamente põe em prática uma série de medidas, como a criação da capitania do Rio Negro, a criação do Diretório dos Índios, a transformação das povoações e aldeias indígenas em vilas portuguesas, a liberdade legal concedida aos índios e a cassação dos poderes temporais da Igreja Católica. A economia da primeira fase colônia, que era baseada na extração de drogas do sertão - extrativismo primário -, transforma-se radicalmente, fundamentando-se na produção manufaturada e na agricultura de pequenas propriedades. A exportação e o consumo local de produtos de borracha alimentavam uma indústria florescente, que produzia artigos de fama mundial, como sapatos e galochas, capas impermeáveis, molas e instrumentos cirúrgicos. Baseava-se também numa vigorosa indústria naval que chegou a produzir mais da metade da frota portuguesa no final do século XVIII. Esta indústria localizava-se em cidades das imediações de Belém, onde ainda estão presentes os sinais da arte portuguesa de construir embarcações. Os mais belos barcos regionais, que lembram os bergantins do século XVIII, continuam a ser fabricados nas tradicionais cidades paraenses e continuam a singrar os rios do grande vale. Quanto à agricultura, a política de pequenas propriedades permitiu a introdução de culturas como as do algodão, anil, tabaco e café, além do rápido crescimento da economia do cacau no baixo Amazonas. O programa agrícola foi reforçado pela vinda de colonos portugueses, culminando com a chegada das famílias oriundas da antiga província de Mazagão. Em 1772, com a expansão e o crescimento dos territórios do oeste, o estado passa a se chamar Grão-Pará e Rio Negro. 


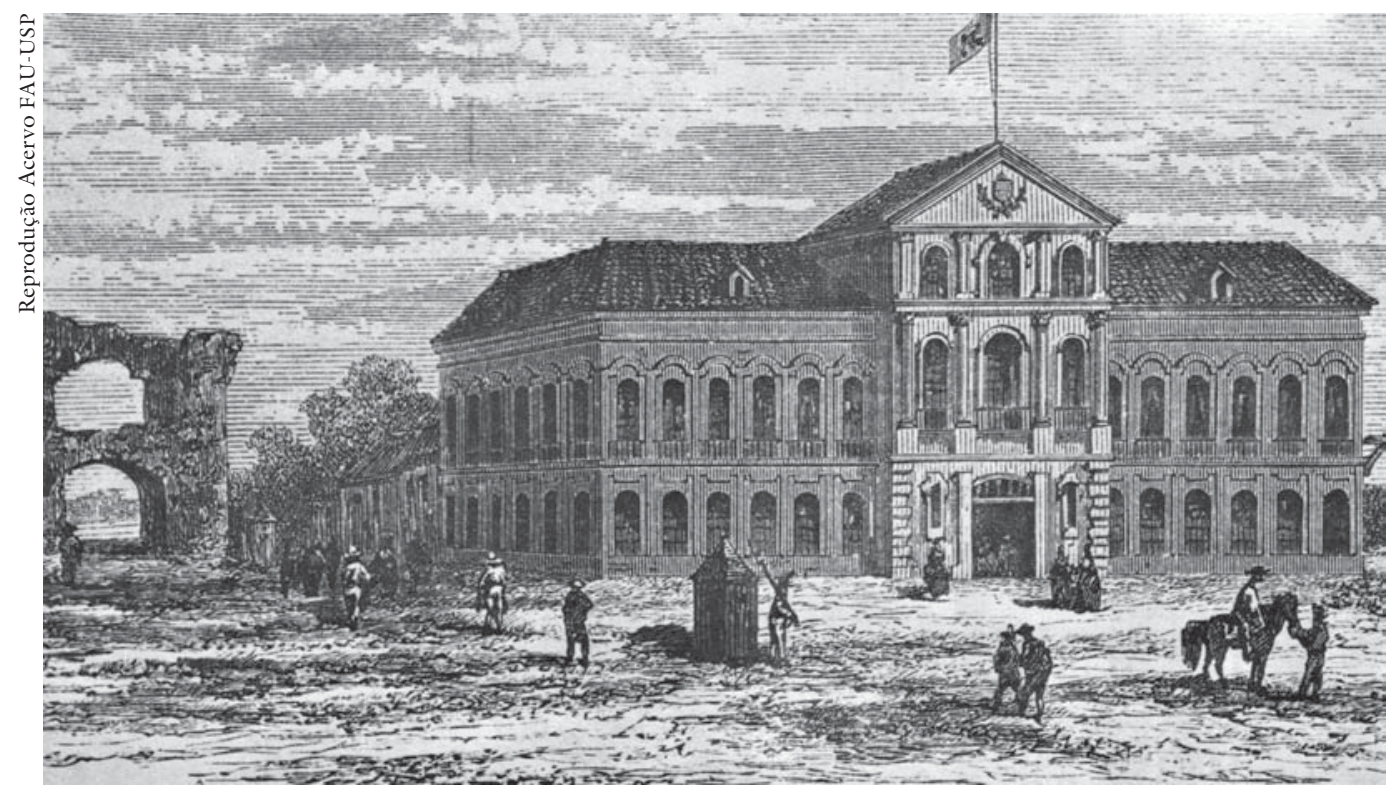

Vista de duas fachadas do Palácio dos Governadores do Grão-Pará, obra de Antônio José Landi.

O Grão-Pará desfrutava de uma cultura urbana bastante desenvolvida, com uma capital de belo traçado e edifícios requintados, onde se pode encontrar exemplares pioneiros da arquitetura neoclássica, obra de Antônio José Landi, o arquiteto de Bolonha contratado por Lisboa para embelezar a cidade de Belém e fazer da miserável aldeia de Barcelos, sede da capitania do Rio Negro, uma cidade habitável. A obra de Landi, um sopro de ar inovador numa época exclusivamente barroca, ainda não foi devidamente avaliada. A vida social de Belém era bastante austera, mas as noites tropicais eram inundadas de música e canto, que vinham das casas particulares e das bandas a animar as praças repletas de transeuntes. É desse período a obra de Tenreiro Aranha, o primeiro escritor de língua portuguesa nativo da região, que também produziu uma interessante obra dramática, que ele mesmo encenou em concorridas e controvertidas produções. Aliás, o teatro era uma das paixões do povo de Belém, e foi ali naquela cidade que algumas das ousadas peças de Gabriel Malagrida, missionário jesuíta, naturalista e místico espanhol que teria a duvidosa honra de ser o último herege a ser queimado na fogueira pela Inquisição, foram encenadas e vistas pela primeira e única vez. A Casa de Ópera de Belém é de 1775 e é no Grão-Pará e Rio Negro que a profissão de ator, por decreto oficial, deixa de ser considerada infame, seguindo uma ordenação de 1771, outorgada pelo rei Dom José I, de Portugal. Vale observar que a Casa de Ópera funcionou até 1812, entrando em decadência depois dos fastos de 1823. Uma das originalidades da sociedade nortista era o papel da mulher. Num olhar superficial, a condição da mulher não parecia distinta do que sucedia em outras partes, mesmo daquelas sociedades que se consideravam mais civilizadas. No entanto, algo de particular existia ali, como a intensa participação das mulheres na política, nos anos que ensangüentaram o GrãoPará. No dia 16 de abril de 1833, é fundada em Belém uma organização secreta 
feminina como nunca houve em outras partes do Brasil. Era a Sociedade das Novas Amazonas, que tinha como finalidade a formação de mulheres com virtudes políticas capazes de dar provas de amor à pátria e adesão à liberdade. Inspiradas nas lendárias amazonas guerreiras, as Iluminadas, com se auto-intitulavam, chegaram a somar mais de mil seguidoras e foram muito influentes. Assim, homens como Tenreiro Aranha, Patroni e o cônego Batista Campos não surgiram do nada, mas foram caudatários de uma civilização própria, em que a tradição cultural ibérica aparece recriada não apenas pelo mundo amazônico, mas absorveu fontes inesperadas, com os ideais da revolução francesa e a filosofia da Ilustração. Deu-se que em 1808, em represália à invasão francesa em Portugal, os nortistas reuniram uma armada e invadiram a Guiana Francesa. Em Caiena funcionava uma delegacia da Revolução, dedicada a traduzir e a editar em espanhol e português as obras de agitação e textos filosóficos, que eram infiltrados nos países vizinhos. As administrações coloniais espanholas e portuguesas temiam tanto esse trabalho que, em Belém, se alguém fosse flagrado portando um desses textos, como, por exemplo, um exemplar da declaração dos direitos do Homem, era preso e sumariamente fuzilado. Por ironia histórica, é naquele antro de subversão, no exato covil onde se destilavam esses "mortíferos venenos", que os nortistas vão se meter e viver durante anos de ocupação, até a assinatura do Tratado de Fontainebleau, em 1814, anos de convívio promíscuo que deram a eles, oficiais e jovens burocratas, acesso a verdadeiras bibliotecas revolucionárias que foram sendo pouco a pouco transferidas para Belém, transportadas nos navios de guerra e sob a proteção daqueles que deveriam confiscá-las.

Talvez por tudo isso, os intelectuais do Grão-Pará tivessem consciência de que não havia salvação fora da adesão ao Império do Brasil. Se continuassem portugueses, numa tentativa de fazer um Canadá português, sofreriam um retrocesso. A administração do ultramar nunca mais seria como antes, nunca mais Portugal teria um Pombal e os portugueses estavam ficando ressentidos e revanchistas como conseqüência de tantos reveses: invasão francesa e transferência da Corte para o Rio de Janeiro; recessão econômica e a independência do Brasil. Havia o risco também de passarem para outras mãos, se tornarem colônia inglesa, ou francesa... Imaginem uma imensa Jamaica equatorial encravada ao norte, fazendo par com a Guiana francesa.

Homens como o cônego Batista Campos sabiam do risco em aderir a um regime monárquico, e ainda por cima com um Imperador português de temperamento brusco no comando, quando o ideal é que o regime fosse republicano. Além disso, estavam se juntando a um país que tinha uma economia completamente diferente e, em certos aspectos, até mais atrasada. A questão é que a economia do Grão-Pará tinha uma participação alta de mão-de-obra assalariada, de gente livre. Os escravos eram minoria, sem peso algum na produção de bens. Já a economia do Império do Brasil não podia funcionar sem escravos. No GrãoPará a cultura não estava marcada pela relação senhor e escravo, pela sordidez do cativeiro, de tal forma que a maioria do povo sequer tinha entrado na cadeia 
produtiva, trabalhando para seu próprio sustento. E nem precisavam se esforçar muito, tamanha a exuberância da natureza. Já no Brasil, não havia massa de gente que não fosse escrava, e todos trabalhavam para algum fazendeiro, porque o sistema era de latifúndios, tal qual no sul dos Estados Unidos, comandados por grandes senhores, gente poderosa que mandava mais que El Rei em seus domínios. No Brasil a indústria era pequena, medíocre e desprezível - produção de estearina, olarias, marcenarias -, e se dizia até que não era vocação do país. No Grão-Pará, nas pequenas fazendas, todos iam juntos lavrar a terra, os proprietários e os empregados, coisa impensável no Brasil. Das colônias portuguesas, o Grão-Pará era a única a possuir uma pauta de exportações onde os produtos manufaturados suplantavam a matéria-prima.

Em compensação, a colônia chamada Brasil dependia amplamente da agricultura e da agroindústria, tendo, portanto, uma forte proporção de mão-deobra escrava. Em meados do século XVIII, tanto o Grão-Pará como o Brasil conseguem criar uma forte classe de comerciantes, bastante ligados à importação e à exportação, senhores de grandes fortunas e bastantes autônomos em relação à Metrópole. Mas enquanto os comerciantes do Rio de Janeiro deliberadamente optaram pela agricultura de trabalho intensivo, como o café, baseando-se no regime da escravidão, os empresários do Grão-Pará intensificaram seus investimentos na indústria naval e nas primeiras fábricas de beneficiamento de produtos extrativos, especialmente o tabaco e a castanha-do-pará. O que as lideranças nortistas queriam, na falta de outra opção, era ocupar o espaço político pós-colonial, fazer com que os líderes brasileiros tivessem neles os seus interlocutores, quando chegasse a hora.

Isto não foi o que aconteceu. A anexação da Amazônia acabou se dando pela força, por que exigia um projeto de nação e uma visão de política continental, coisa que nem os nortistas nem os brasileiros tinham. E entre 1823 e 1840, o que vai se ver é um processo de provocação deliberada por parte do Rio de Janeiro e a fúria crescente da parte do Grão-Pará. O resultado foi uma severa convulsão social e a conseqüente repressão.

O mais importante historiador do período, Domingos Antonio Rayol, Barão de Guajará, resume as responsabilidades dos homens de seu tempo e demonstra que os protagonistas a se digladiarem em lutas fratricidas, tratando cada um de desmoralizar por sua vez o princípio de autoridade, arrastando as massas populares aos movimentos tumultuários, apagando nelas a noção dos deveres sociais, cavando o abismo em que mais tarde uns e outros se precipitaram, com irreparável dano e ruína geral da Província.

Entre 1823 e 1840, a região norte sofre a intervenção política e militar do Império do Brasil, perde suas lideranças históricas e deixa de ser uma administração colonial autônoma para se transformar numa fronteira econômica. A derrota do Grão-Pará e sua destruição pelo Império do Brasil, se me permitem a comparação um tanto audaciosa, foi, de certo modo, como se o Sul tivesse vencido a 
Guerra de Secessão, nos Estados Unidos. Dezessete anos de guerra civil levaram a Amazônia a perder $40 \%$ dos seus habitantes. A anexação destruiu todos os focos de prosperidade. Entre os políticos do Império do Brasil e as lideranças nortistas nenhum diálogo foi possível. E o vento levou o Grão-Pará.

O Brasil é fruto de opções históricas como essa que acabamos de resumir. Evidentemente que opções erradas não são exclusivas de nossa história, mas o problema é que a elas se colam os efeitos de uma perversa dicotomia, como se o país se configurasse por um eterno embate entre áreas endemicamente pobres e áreas historicamente ricas, entre regiões intrinsecamente modernas e outras atavicamente arcaicas. Nesse falso pressuposto, o Norte e o Nordeste representam o arcaico, o atraso, um fardo que o Centro-Sul moderno precisa financiar, empurrar e suportar. Por tudo que vimos até agora, esta oposição arcaísmomodernidade não estaria sendo vista do avesso?

Acervo Fundação Oswaldo Cruz

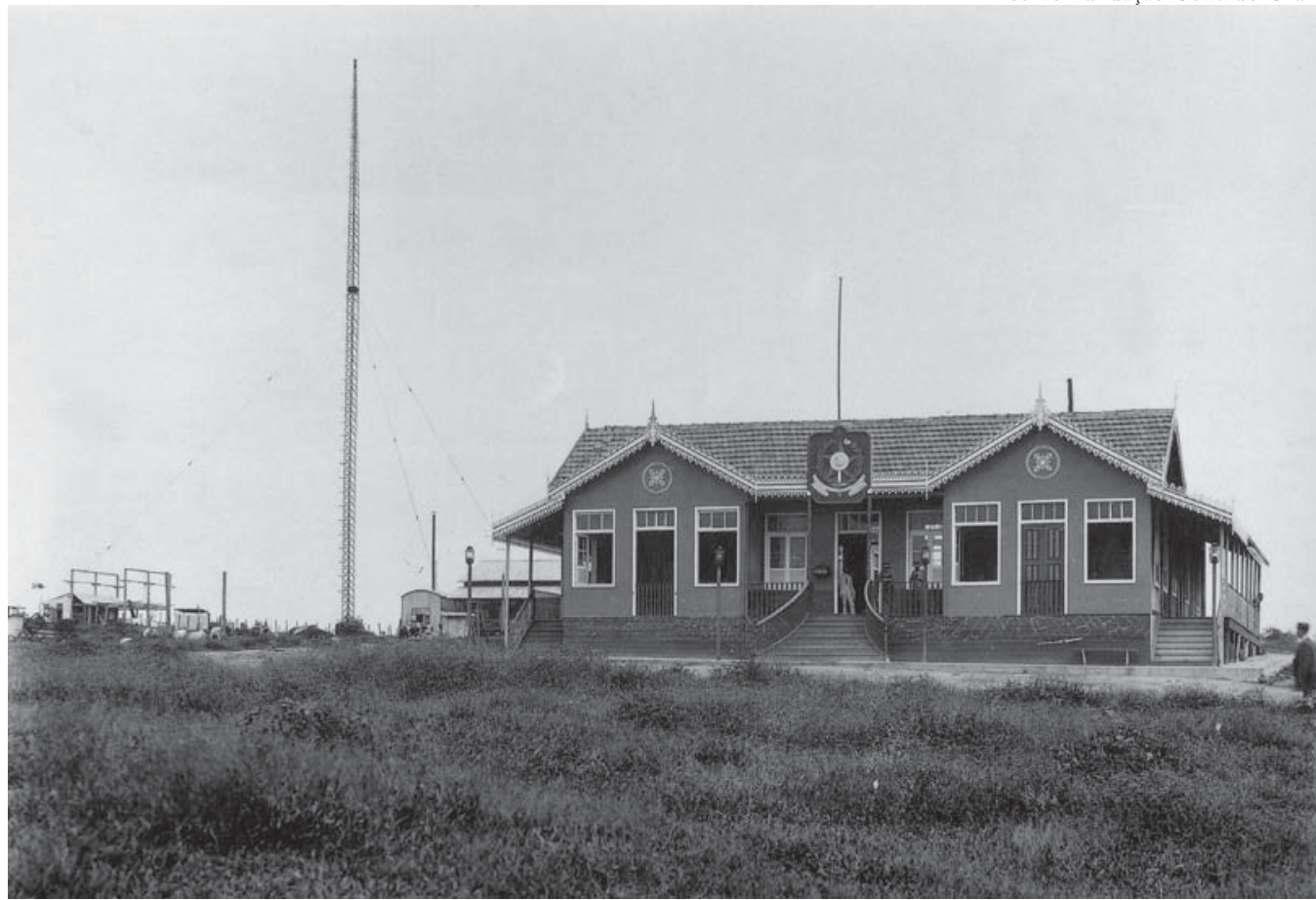

Prefeitura de Rio Branco (Acre), dezembro de 1912.

Certamente, no caso da Amazônia, o rótulo de região atrasada tem sido foco de desastres. É aqui que reside o problema. Especialmente porque se há uma região brasileira que melhor conheça a experiência da modernidade, esta é a Amazônia, como prova a sua própria história. Nos quinhentos anos de presença da cultura européia, experimentou os métodos mais modernos de exploração. Cada uma das fases da história regional mostra a modernidade das experiências que foram se sucedendo: agricultura capitalista de pequenos proprietários em 1760 com o Marquês de Pombal, economia extrativista exportadora em 1890 com a borracha, e estrutura industrial eletroeletrônica em 1970 com a Zona 
Franca de Manaus. Os habitantes da Amazônia, portanto, não se assustam facilmente com problemas de modernidade, o que vem provar que a região é bem mais surpreendente, complexa e senhora de um perfil civilizatório insuspeito pela vã ingenuidade. Não é por outro motivo que a Amazônia continua um conveniente mistério para os brasileiros. Portanto, vamos com calma quando aplicarmos esses rótulos.

Experiências de modernidade já foram feitas na região. Mas os tecnocratas e o governo central foram incapazes de favorecer a aceitação de experiências locais no processo de integração econômica, porque de uma área atrasada nada se espera.

Isto aparece claramente com o projeto agropecuário da ditadura militar. $\mathrm{O}$ estímulo para a criação de gado tornou-se uma catástrofe para a Amazônia porque o modelo agropecuário foi imposto a um estado, o Acre, onde não havia tradição de criação de gado, e que por causa disso perdeu sua cobertura florestal tradicional. Enquanto os tecnocratas de Brasília mandavam boi para os sertões do Acre, os nativos se perguntavam: por que não usaram as zonas tradicionais de pasto? Sim, pastos naturais como os existentes no baixo Amazonas, na região de Óbidos, Alemquer e Oriximiná, ou em Roraima, cuia superfície é superior à de todos os pastos europeus reunidos? Esse é exatamente um caso em que a integrarão econômica foi feita em detrimento da história e da tradição locais. E, no entanto, a arrogância não ficou apenas com os tecnocratas do governo militar, um contingente imenso de salvadores da pobre e atrasada Amazônia estabeleceu suas agendas baseadas em conclusões apressadas.

Por exemplo, as propostas de neo-extrativismo de Chico Mendes tomadas como solução universal para a questão amazônica. Para começo de conversa, elas se destinavam apenas a dois ou três municípios do Acre. Chico Mendes era de Xapuri, quase na fronteira com a Bolívia. Em Cruzeiro do Sul, alguns quilômetros para o norte, não serviam mais. Era, portanto, absurdo focalizar-se nelas e apresentá-las como soluções de uso geral na região, como fizeram alguns ecologistas e certos movimentos de defesa da região. Nos parâmetros políticos de 1985, quando a idéia foi gerada, a luta por tais reservas extrativistas estava perfeitamente explicada. No entanto, este foi um conceito que muito foi alargado desde então, a ponto de se tornar uma das mais usadas medidas "de preservação" do governo Sarney e, em termos políticos amplos, como espécie de proposta geral para a região, pois o "futuro" da Amazônia estaria em sua total regressão à economia extrativista.

O extrativismo foi o subsistema econômico engendrado pelo chamado ciclo da borracha. O seu impacto acabou por imprimir a face social da Amazônia, criando uma peculiar cultura, determinando sua estrutura de classes e até mesmo as formas de ocupação do espaço geográfico. Estou convencido de que Chico Mendes, como todo nativo da região, conhecia muito bem o caráter da velha sociedade extrativista, especialmente o caráter dos proprietários extrativistas, in- 
capazes de enfrentar o modelo agropecuário e de defender suas propriedades. As reservas extrativistas foram uma brilhante solução tática para preencher esse vazio político. Era uma forma de mobilizar os seringueiros para a defesa da propriedade extrativista, já que os proprietários estavam enfraquecidos, postos à margem pelo modelo econômico agropecuário e especulador.

Uma economia como a extrativista, que sequer formou uma oligarquia firme em seus propósitos, não pode servir de modelo de restauração salvadora. Os proprietários extrativistas foram saindo de cena, consumindo o melhor de sua energia e capacidade criadora no exercício de sobreviver a qualquer custo. Durante o tempo em que estiveram parasitando a natureza da região, os extrativistas relacionaram-se com os grupos hegemônicos do país através de uma lamentável sublimação política. Fingiam que tinham o poder, encenavam os seus desejos e, no final, acabavam por conciliar, seguindo a reboque com a sensação do dever cumprido.

Chico Mendes não estava fazendo nenhum tipo de apologia restauradora de uma página negra da história regional ao propor a luta pela transformação dos seringais acreanos em reservas. Ele sabia que tais reservas eram soluções muito localizadas, que não respondiam sequer ao problema do Acre, quanto mais de uma área continental, diversificada, como a Amazônia brasileira. Falar, portanto, que o destino da Amazônia é a regressão ao extrativismo, mesmo a um extrativismo idílico, socializado e místico, é mais uma vez atropelar a própria Amazônia. De qualquer modo, vamos supor que fosse possível fazer da Amazônia uma imensa reserva extrativista, um enorme playground para todos os diversos "pirados" da terra. Bem, este é o sonho nada pirado da poderosa indústria farmacêutica internacional, dos grupos econômicos que trabalham com a biotecnologia, com a engenharia genética e a etnobiologia. Assim, mais uma vez deseja-se que a Amazônia ofereça o que tem, mas que fique em seu lugar, como território primitivo, de gente primitiva, que não deve jamais ter acesso a essas tecnologias e ao controle econômico de seus produtos.

O certo é que se o extrativismo na Amazônia não está morto, deve ser definitivamente erradicado por qualquer plano que respeite o processo histórico e a vontade regional. Mesmo porque a Amazônia não deve ser reserva de nada, nem celeiro, nem estoque genético ou espaço do rústico para deleite dos turistas pós-industriais.

Infelizmente, o modelo econômico brasileiro insiste em destruir riquezas que sequer foram computadas, movido por puro imediatismo econômico. Mas não se deve agravar mais a região impondo-se soluções aparentemente ditadas pelo espírito da solidariedade. Especialmente porque contra os abusos é possível resistir, mas não há nada que se possa fazer contra a solidariedade.

Se o Império do Brasil não tivesse tido que se haver com o Grão-Pará, ou, como disse José Honório Rodrigues, se não tivesse passado o tempo inteiro reprimindo revoltas populares, podemos estar certos de que o processo de for- 
mação da sociedade brasileira teria chegado a outro resultado. Na realidade, o Grão-Pará foi reinventado em Amazônia pelo Império do Brasil, que propôs para a região derrotada uma nova e conveniente imagem, que ainda não se ajustou totalmente e às vezes causa desconforto. Os nativos da Amazônia sempre se espantam ao ver que, talvez para melhor vendê-la e explorá-la, ainda apresentam sua região como habitada essencialmente por tribos indígenas, quando existem há muito tempo cidades, uma verdadeira vida urbana, e uma população culta que teceu laços estreitos com o mundo desde o século XIX. Aliás, nisso residem as maiores possibilidades de resistência e de sobrevivência da região. Com efeito, os povos indígenas da Amazônia há muito se conscientizaram de que nada conseguirão se não se apoiarem nessa população urbana que é única e que se expressa nas eleições e exerce pressão sobre a cena política. É pela participação política dessa Amazônia urbana, reforçando o jogo das forças políticas avançadas na construção da democracia, que o problema da própria exploração econômica da Amazônia poderá encontrar uma solução. Portanto, é preciso reforçar as estruturas políticas regionais. A Amazônia conta uma população de vinte milhões de pessoas e com nove milhões de eleitores, o que não é pouca coisa.

Márcio Souza é romancista, autor da tetralogia Crônicas do Grão-Pará e Rio Negro. Texto solicitado ao autor. Recebido e aceito para publicação em 31 de janeiro de 2005. 